Article

\title{
Evaluation and Characterization of Tamarind Gum Polysaccharide: The Biopolymer
}

\author{
Rishabha Malviya ${ }^{1,+}$, Sonali Sundram ${ }^{1,+}$, Shivkanya Fuloria ${ }^{2, *}$, Vetriselvan Subramaniyan ${ }^{3}$ (D), \\ Kathiresan V. Sathasivam ${ }^{4}$, Abul Kalam Azad ${ }^{5}$ D, Mahendran Sekar ${ }^{6}$ (D), Darnal Hari Kumar ${ }^{7}$, \\ Srikumar Chakravarthi ${ }^{3}$, Omji Porwal ${ }^{8}$, Dhanalekshmi Unnikrishnan Meenakshi ${ }^{9}{ }^{D}$ \\ and Neeraj Kumar Fuloria ${ }^{2, *}$
}

check for updates

Citation: Malviya, R.; Sundram, S.; Fuloria, S.; Subramaniyan, V.; Sathasivam, K.V.; Azad, A.K.; Sekar M.; Kumar, D.H.; Chakravarthi, S.; Porwal, O.; et al. Evaluation and Characterization of Tamarind Gum Polysaccharide: The Biopolymer. Polymers 2021, 13, 3023. https:// doi.org/10.3390/polym13183023

Academic Editors: Carlo Santulli and Vincenzo Fiore

Received: 5 August 2021

Accepted: 1 September 2021

Published: 7 September 2021

Publisher's Note: MDPI stays neutral with regard to jurisdictional claims in published maps and institutional affiliations.

Copyright: (c) 2021 by the authors. Licensee MDPI, Basel, Switzerland. This article is an open access article distributed under the terms and conditions of the Creative Commons Attribution (CC BY) license (https:// creativecommons.org/licenses/by/ $4.0 /)$.
1 Department of Pharmacy, School of Medical \& Allied Sciences, Galgotias University, Greater Noida 201310, Uttar Pradesh, India; rishabha.malviya@galgotiasuniversity.edu.in (R.M.); sonali.sundram@galgotiasuniversity.edu.in (S.S.)

2 Faculty of Pharmacy, Centre of Excellence for Biomaterials Engineering, AIMST University, Bedong 08100, Kedah, Malaysia

3 Faculty of Medicine, Bioscience and Nursing, MAHSA University, Jalan SP 2, Bandar Saujana Putra, Jenjarom 42610, Selangor, Malaysia; drvetriselvan@mahsa.edu.my (V.S.); srikumar@mahsa.edu.my (S.C.)

4 Faculty of Applied Science, Centre of Excellence for Biomaterials Engineering, AIMST University, Bedong 08100, Kedah, Malaysia; skathir@aimst.edu.my

5 Advanced Drug Delivery Laboratory, Faculty of Pharmacy, International Islamic University Malaysia, Kuantan 25200, Pahang Darul Makmur, Malaysia; azad2011iium@gmail.com

6 Department of Pharmaceutical Chemistry, Faculty of Pharmacy and Health Sciences, Universiti Kuala Lumpur Royal College of Medicine Perak, Ipoh 30450, Perak, Malaysia; mahendransekar@unikl.edu.my

7 Jeffrey Cheah School of Medicine \& Health Sciences, Monash University, No.3 Jalan Masjid Abu Bakar, 80100 Johor Bahru, Johor, Malaysia; hari.kumar@monash.edu

8 Department of Pharmacognosy, Tishk International University, Erbil 44001, Iraq; omji.porwal@tiu.edu.iq

9 College of Pharmacy, National University of Science and Technology, Muscat 130, Oman; dhanalekshmi@nu.edu.om

* Correspondence: shivkanya_fuloria@aimst.edu.my (S.F.); neerajkumar@aimst.edu.my (N.K.F.); Tel.: +60-143034057 (S.F.); +60-164037685 (N.K.F.)

+ These authors contributed equally to this work.

Abstract: Polymers from natural sources are widely used as excipients in the formulation of pharmaceutical dosage forms. The objective of this study was to extract and further characterize the tamarind gum polysaccharide (TGP) obtained from Tamarindus indica as an excipient for biomedical applications. Double distilled water was used as a solvent for the extraction of gum while Ethyl alcohol was used as an antisolvent for the precipitation. The results of the Hausner ratio, Carr's index and angle of repose were found to be $0.94,6.25$, and 0.14 , respectively, which revealed that the powder is free-flowing with good flowability. The gum was investigated for purity by carrying out chemical tests for different phytochemical constituents and only carbohydrates were found to be present. The swelling index was found to be $87 \pm 1 \%$, which shows that TGP has good water intake capacity. The $\mathrm{pH}$ of the $1 \%$ gum solution was found to be neutral, approximately $6.70 \pm 0.01$. The ash values such as total ash, sulphated ash, acid insoluble ash, and water-soluble ash were found to be $14.00 \pm 1.00 \%, 13.00 \pm 0.05 \%, 14.04 \pm 0.57 \%$ and $7.29 \pm 0.06 \%$, respectively. The IR spectra confirmed the presence of alcohol, amines, ketones, anhydrides groups. The contact angle was $<90^{\circ}$, indicating favorable wetting and good spreading of liquid over the surface The scanning electron micrograph (SEM) revealed that the particle is spherical in shape and irregular. DSC analysis shows a sharp exothermic peak at $350{ }^{\circ} \mathrm{C}$ that shows its crystalline nature. The results of the evaluated properties showed that TGP has acceptable properties and can be used as a excipient to formulate dosage forms for biomedical applications.

Keywords: tamarind gum; polysaccharides; micromeritic properties; pharmaceutical excipients 


\section{Introduction}

Natural polymers usually have unique properties that distinguish them from synthetic polymers, and tamarind gum polysaccharide (TGP) is one of them. TGP has a wide range of beneficial properties that makes it a suitable excipient for various applications [1]. Tamarind is a large evergreen tree that grows abundantly in the dry regions of Central and South India, as well as other Southeast Asian nations [2]. Plant-derived polysaccharides have piqued interest due to their wide range of pharmaceutical applications, including diluents, binder, and disintegrants in tablet formulation, thickeners in oral liquids, protective colloids in suspensions, gelling agents in gels, and bases in suppository formulation.

TGP is a plant polysaccharide derived from the Tamarindus indica Linn seed endosperm from Fabaceae family. TGP have $1735 \mathrm{kDa}$ molecular weight [3]. It is a water-soluble, nonionic, branched polysaccharide with hydrophilic, gel-forming, and mucoadhesive characteristics [4]. TGP is also biodegradable, biocompatible, noncarcinogenic, and irritant-free. It is used in the pharmaceutical, cosmetic, and food industries as a promising biopolymer [5]. In recent years, it has been extensively studied and used as a successful pharmaceutical excipient in a variety of drug delivery applications. Tamarind gum is used in the development of drug delivery systems for the oral, intestinal, ophthalmic, buccal, and nasal routes [6]. The chemical structure of tamarind seed polymer are shown in Figure 1.

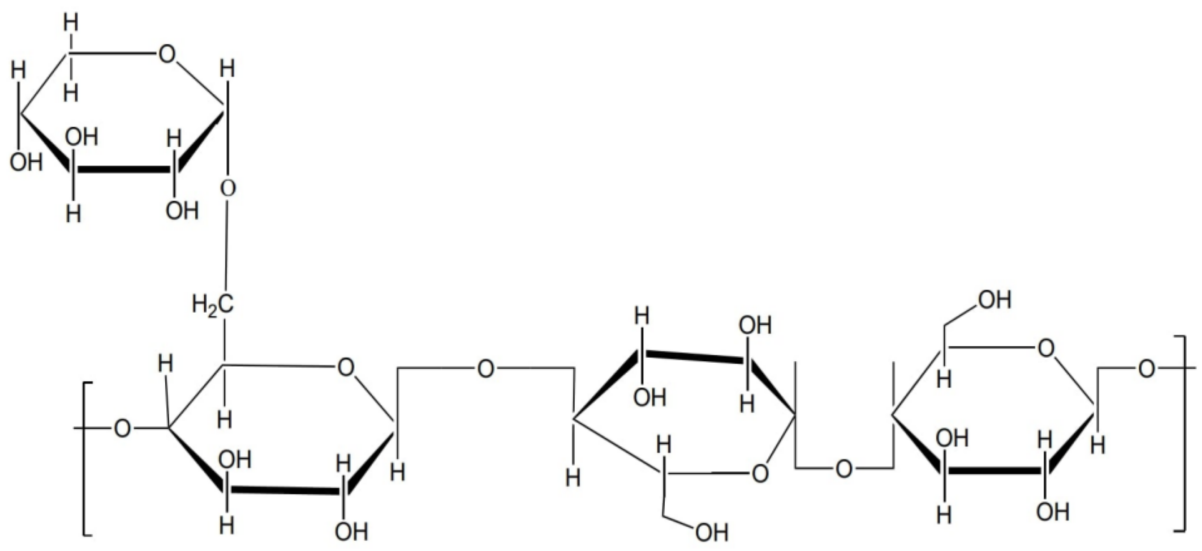

Figure 1. Chemical structure of tamarind seed polymer.

Gums, also known as polysaccharides, are water-soluble complex carbohydrates that may be used to make gels and mucilages. Galactose, arabinose, rhamnose, xylose, and galacturonic acid are only a few of the sugars that may be used to make them [7]. They have gelling, thickening, moisture retention, emulsification, and stabilizing properties. Polysaccharides are frequently utilized in food product manufacturing due to their versatility [8]. Its chemical structures are closely connected to its wide range of uses. The characteristics of polysaccharide or glycoconjugate can be determined by analyzing structural molecules properties [9].

The seed of the tamarind contains around $65 \%$ of the gum and might be utilized to develop specific drug delivery systems. The polysaccharide that is present in TGP is known as tamarind seed polysaccharide [10]. The physicochemical characteristics of TGP may be improved by converting it to carboxymethyl tamarind gum. TGP has certain important limitations, besides its suitability for therapeutic uses. The color of TGP is dull, and it has a characteristics odor [11]. T. indica extracts were found to exhibit antibacterial, antifungal, hypoglycaemic, cholesterolemic, cytotoxic, anti-inflammatory, gastrointestinal, hypolipomic, and antioxidant properties in pharmacological studies. The phytochemical analysis of a methanolic extract of $T$. indica leaves yielded two triterpenes, lupanone and lupeol. Scientists were prompted to chemically alter its functional groups due to its insolubility in water and deterioration in an aquatic environment [12]. Various modifications which have 
been executed till date include carboxymethylation, acetylation, hydroxyl-alkylation and thiolisation, polymer grafting [13].

The solubility, viscosity, swelling, and stability of tamarind gum have all changed as a result of these changes. TGP and CMTG have been employed to develop a variety of drug delivery systems [14]. Accordingly, there is a need to investigate TG's physicochemical characteristics to identify its suitability as an excipient in the development of drug delivery systems. As a result, research was conducted to extract, modify, and characterize tamarind gum [15]. TGP is a highly viscous, mucoadhesive, and biocompatible natural polymer; it is also suitable for ocular drug delivery and preparation of ophthalmic medicaments. It has been used as a polymer for the formulation of ophthalmic drug delivery. Because the eye is such a sensitive organ and an immune privileged region, the biocompatibility of the polymers plays an important role in ocular drug delivery systems [16-18].

Various functionally derivatized TGP has recently gained popularity as potential pharmaceutical excipients in a variety of improved drug delivery systems, owing to their improved stability (lower degradability) [19]. These functionally derivatized tamarind gums have improved mechanical behavior and are capable of regulating drug release over a longer period. The present study deals with a detailed evaluation of several types of tamarind gum functionalizations for application in the development of better drug delivery systems. The first section discusses the origins, components, characteristics, and applications of tamarind gum. The latter section provides a thorough examination of tamarind gum functionalizations in drug administration $[19,20]$.

\section{Materials and Methods}

Ethyl alcohol $(90 \% v / v)$ was purchased from Sigma Aldrich Pvt. Ltd., Bangalore, India. All other chemicals are procured from HiMedia Laboratories Pvt. Ltd., Mumbai, India. All the reagents are analytical grade and used as supplied.

\subsection{Collection of Plant Material}

Crude plant material (Tamarindus indica) was purchased from a local shop in Greater Noida, India. The collected plant material was identified by the Department of Biotechnology, Gautam Buddha University (State Govt. University) Greater Noida, Uttar Pradesh, India.

\subsection{Extraction of Gum}

Extraction of Tamarind Gum Polymer

The test of the seeds of tamarind was removed by drying it in a hot air oven for $20 \mathrm{~min}$ at $40{ }^{\circ} \mathrm{C}$. Then the seed coat was removed by simply crushing from the aside. The obtained white portions of the seeds were then utilized for the isolation technique. The seeds were immersed in a beaker with double distilled water and provided heating conditions till $40{ }^{\circ} \mathrm{C}$. After extraction the supernatant fluid was discarded after the centrifugation technique. Then, the remaining portion was concentrated by heating them again at a constant temperature of $40^{\circ} \mathrm{C}$. The whole slurry was filtered and precipitate using ethyl alcohol. Then the precipitated product was spread on the petri dish and dried and size was reduced till fine powder was obtained [20,21].

\subsection{Physicochemical Characterization of Gum}

All the following physicochemical charcaterizations were carried out at $25 \pm 2{ }^{\circ} \mathrm{C}$.

\subsubsection{Identification Tests for Carbohydrates, Proteins, Tannins}

The aqueous solution of extracted gum was used for chemical characterization. Test for carbohydrates, proteins, alkaloids, lipids, tannins, glycosides were performed according to the standard procedure $[22,23]$. 
Test for Carbohydrates

One percent of the solution of TGP was prepared in distilled water. 2 drops of $\alpha$ naphthol was added to the solution in the test tube. The test tube was inclined carefully and $1 \mathrm{~mL}$ concentrated sulfuric acid was poured dropwise. Violet color appeared at the junction of the two liquids [24].

\section{Test for Proteins}

One percent of the solution of TGP was prepared using double distilled water, Biuret reagent was added. The presence of red color indicates the absence of proteins [25].

Test for Glycosides

Pure TGP was dissolved in a mixture of $1 \%$ ferric sulphate solution in (5\%) glacial acetic acid. Add one or two drops of concentrated sulfuric acid. The red color was obtained due to the presence of 2-deoxy [26].

Test for Tannins

In the native TGP, $5 \%$ ferric chloride was added and boiled. The absence of greenish precipitate was an indication of an absence of tannins.

Test for Alkaloids

One percent of the sample solution was prepared and Dragendorff's reagent was added. No brick red precipitates were obtained. Glycoside was found to be absent.

\section{Sudan Red-III Test}

To 1\% sample solution of TGP, Sudan red III was added. No change in the color of the solution detects the absence of lipids in the polymer [27].

\subsubsection{Organoleptic Properties}

The gum was characterized for organoleptic properties such as; taste as color, odour and texture.

\subsection{3. $\mathrm{pH}$ of Gum}

Firstly, the tamarind gum polysaccharide was weighed and then dissolved in water separately to get a $1 \% w / v$ solution. The $\mathrm{pH}$ of the solution was determined by using a digital $\mathrm{pH}$ meter (DECIBLE, Chandigarh, India). $\mathrm{pH}$ instrument was calibrated using standard $\mathrm{pH}$ solutions 7 and 4 . For the preparation of the standard solution, buffer capsules of $\mathrm{pH} 7$ and $\mathrm{pH} 4$ were dissolved in $100 \mathrm{~mL}$ of double-distilled water. Further, the gum solution was poured into a beaker $(50 \mathrm{~mL})$ to determine the $\mathrm{pH}\left(25 \pm 2{ }^{\circ} \mathrm{C}\right)$.

\subsubsection{Viscosity of Gum}

TGP was dissolved in an aqueous solution and filtered. 1\% w/v solution of TGP was prepared. A relative density bottle is used to determine the density of the polymer solution. To determine the thermodynamic parameter, calibrated laboratory scale thermometer was used $\left(25 \pm 2{ }^{\circ} \mathrm{C}\right)$. The time is noted in triplicate and then the viscosity is calculated. The viscosity of the prepared $1 \% w / v$ solution of gum $(25 \mathrm{~mL})$ was measured using Ostwald viscometer [28]. Initially, the density of the solution was determined using a relative density bottle. The solution was then filled in the Ostwald viscometer and time was noted. Further, the viscosity of the sample was calculated using Equation (1) [29].

$$
\frac{\eta 2}{\eta 1}=\frac{\sigma 2-\mathrm{t} 2}{\sigma 1-\mathrm{t} 1}
$$

where $\eta 2$ = viscosity of sample, $\eta 1=$ viscosity of water, $\sigma 2$ = density of sample, $\sigma 1=$ density of water, $\mathrm{t} 2=$ time taken by the sample, and $\mathrm{t} 2=$ time taken by water. 


\subsubsection{Surface Tension}

The surface tension of prepared $1 \% w / v$ solution of gum $(25 \mathrm{~mL})$ was measured using a stalagmometer $\left(25 \pm 2{ }^{\circ} \mathrm{C}\right)$. Initially, the density of the solution was determined using a relative density bottle. The solution was then filled in the stalagmometer through capillary action and the time of the drop falling was noted. Further, the surface tension of the sample was calculated using Equation (2) [30].

$$
\frac{\gamma 2}{\gamma 1}=\frac{\eta 1 \cdot \sigma 2}{\eta 2 \cdot \sigma 1}
$$

where $\gamma 2=$ surface tension of the sample, $\gamma 1=$ surface tension of sample, $\eta 2=$ Viscosity of sample, $\eta 1=$ Viscosity of water, $\sigma 2=$ Density of sample, and $\sigma 1=$ Density of water.

\subsubsection{Swelling Index}

The swelling index of the tamarind gum polysaccharide was calculated by weighing a butter paper of size $2.2 \mathrm{~cm}$. Further butter paper was dipped in a petridish contain $15 \mathrm{~mL}$ of water. $0.1 \mathrm{gm}$ of the powdered sample was kept over butter paper placed in a petridish and the weight of swelled TGP was measured a after $24 \mathrm{~h}$ at $25 \pm 2{ }^{\circ} \mathrm{C}$, and the final swelling index was calculated by Equation (3) [31].

$$
\text { Swelling index }=\frac{\text { Initial weight }- \text { final weight }}{\text { Initial weight }} \times 100
$$

\subsubsection{Bulk Density and Bulkiness}

Inverse bulk density was known as bulkiness. For bulk density determination, an accurately weighed quantity of sample ( $5 \mathrm{gm}$ ) was placed in a measuring cylinder. The cylinder was fixed on the bulk density apparatus and the volume occupied by the powder was noted at $25 \pm 2{ }^{\circ} \mathrm{C}$. Bulk density was calculated in Equation (4).

$$
\text { Bulk Density }=\frac{\text { Weight of powder }}{\text { weight of apparent volume }}
$$

\subsubsection{Powder Compressibility (Carr's Compressibility Index)}

Finely powdered tamarind gum polysaccharide ( $5 \mathrm{~g}$ ) was taken and transferred into measuring cylinder and calculations were done using bulk density apparatus. Finally, Carr's index was calculated at $25 \pm 2{ }^{\circ} \mathrm{C}$ using Equation (5).

$$
\text { Car r's index }=\frac{\text { Tapped density }- \text { bulk density }}{\text { tapped density }} \times 100
$$

\subsubsection{Powder Flow Property}

Flow characteristics were measured by the angle of repose. TGP $(5 \mathrm{~g})$ was poured from a funnel which was kept at a distance of $5 \mathrm{~cm}$ from the surface. The TGP formed a heap of a pile on the surface from where the radius can be calculated. The angle of repose can be determined using Equation (6).

$$
\tan \theta=\mathrm{h} / \mathrm{r}
$$

where, $\mathrm{h}=$ height of pile, and $\mathrm{r}=$ radius of pile

\subsection{For Powder Blend}

The randomly picked sample were analyzed using a microscope to determine the minor and major axis length. The size of the particles was determined [32,33]. 


\subsubsection{Aspect Ratio}

Aspect ratio is a term that describes the ratio between the size of a geometric shape and different sizes of them. The aspect ratio varies between 0 and 1 with a less value indicative of an elongated particle and circle having an aspect ratio of 1 . The aspect ratio is "the proportional relationship between a minimum and maximum diameter of the particles.

$$
\text { Aspect ratio }=\frac{b}{1}
$$

where $b=$ minimum diameter of the particles, and $1=$ maximum diameter of the particles Roundness

Roundness is a measure of how closely the shape of the powder? It is based on the ratio between inscribed and the circumscribed circles that is the minimum and maximum sizes of the particles. The powder resembles a circle a perfect circle has a roundness value of 1 .

$$
\text { Roundness }=\frac{4 \times \pi \times \mathrm{A}}{(\mathrm{P})^{2}}
$$

where, $\mathrm{A}=$ projected area of the particles, and $\mathrm{P}=$ perimeter of the particles,

Irregularity (IR)

Irregularity measure the surface area as compared to the size of the particle.

$$
\text { Irregularity }=\frac{\mathrm{P}}{\mathrm{L}}
$$

where, $\mathrm{P}=$ perimeter of the particles and $\mathrm{L}=$ maximum diameter

\section{Elongation Ratio}

The elongation ratio can be determined by "the proportional relationship between the maximum and minimum diameter of the particles.

$$
\text { Elongation ratio }=\frac{1}{\mathrm{~b}}
$$

where, $1=$ Maximum length of the particle and $b=$ Minimum length of the particle

Equivalent Circle Diameter (ECD)

Equivalent circle diameter can be determined by the diameter of the particle with the same cross-section area as the powder. The greater the equivalent circle diameter, the higher the mean particle size.

$$
\text { Equivalent circle diameter }=\sqrt[2]{\mathrm{A} / \pi}
$$

where, $\mathrm{A}=$ projected area of the particle.

\section{Hausner Ratio}

It can be determined by the flowability of the powder. It is also used in industries as an indication of the flowability of the powder. A Hausner ratio is greater than 1.25 , so it's can be indicating poor flowability.

$$
\text { Hausner Ratio }=\frac{\text { Tapped Density }}{\text { Bulk Density }}
$$


Angle of Internal Friction (AIF)

Angle of internal friction is determining the relationship between the porosity and the number of taps. The AIF is derived by determining the angle made between the straight line and the abscissa.

$$
\mathrm{K}=\varepsilon^{2} \mathrm{~N} /(1-\varepsilon)
$$

where, $\mathrm{N}=$ number of taps and $\varepsilon=$ porosity.

Porosity $(\varepsilon)$

The porosity is based on the apparent density (bulk density) and the true density of the compacted powders.

$$
\varepsilon=1-\frac{\text { Apparent Density }}{\text { True Density }}
$$

\subsection{Ash Value Determination}

\subsubsection{Total Ash Value}

$1 \mathrm{~g}$ of TGP was taken in a crucible and ignited at a temperature of $600-700{ }^{\circ} \mathrm{C}$. After $5 \mathrm{~min}$, the ash was removed and was weighed till constant weight is achieved [34].

\subsubsection{Sulphated Ash Value}

The preheated crucible was taken in which $1 \mathrm{~g}$ of the TGP was added. The material was ignited and converted to ash. Slightly moisten the content with dilute sulphuric acid and gently heat it, until white fumes are evolved. Calculate the weight of sulphated ash with respect to the air-dried TGP [34].

\subsubsection{Water-Soluble Ash}

Initially convert the native TGP into ash and boil it with $25 \mathrm{~mL}$ distilled water for $5 \mathrm{~min}$. Wash it thoroughly and weigh it. Subtract the weight of insoluble matter from the weight of the ash. Calculate the percentage of water-soluble ashes present [34].

\subsubsection{Acid Insoluble Ash}

Initially convert the native TGP into ash and boil it with $25 \mathrm{~mL}$ dilute hydrochloric acid for $5 \mathrm{~min}$. Collect the matter in the crucible and wash it thoroughly with water. Weight the content and calculate the acid insoluble ash present [34].

\subsection{Particle Size Analysis}

Particle size was determined by using optical microscopy. In the sample preparation, a 100 microliters sample was placed over a slide and cover with the help of a coverslip with gentle pressure to achieve a sample thickness of $\sim 25$ micrometers. Calibration of optical microscope was done by ocular and stage micrometre scale. After calibration, the least count of stage scale was determined and no. of particles (approx. 60 particles) lies in between scale was noted and calculated $[35,36]$.

\subsection{FT-IR Spectral Analysis}

The FTIR spectral analysis of TGP was performed using an Alpha Bruker ATR FTIR spectrophotometer (Alpha, ECD-ATR; Bruker Peoria, IL, USA). The sample is prepared by filling the ATR's analyser plate with dried powdered samples directly. The spectrums were recorded in transmittance mode with 66 scans and a resolution of $2 \mathrm{~cm}^{-1}$ from 4000 to $600 \mathrm{~cm}^{-1}$. The spectra obtained were recorded and analysed to determine the functional groups present in the polysaccharide [37]. 32 scans were done and averaged to achieve a satisfactory signal-to-noise ratio [38]. 


\subsection{Contact Angle Determination}

The measuring of contact angle is an essential factor in determining wetting ability. A Rame goniometer model 100-00-230 (Rame-Hart-Instrument Co., Succasunna, NJ, USA) was used to calculate the contact angle. The contact angle was determined using a Rame goniometer as a direct tool. An aqueous solution of samples $(1 \% w / v)$ was produced and cast on a glass surface, then vacuum dried at $40{ }^{\circ} \mathrm{C}$ [37].

\subsection{Scanning Electron Microscopy Analysis (SEM)}

SEM is generally used to determine the morphology of samples. The scanning electron microscope (SEM) was used to examine the surface characteristics of TGP. Using a Zeiss EVO 18 analyzer (ZEISS Research Microscopy Solutions, Jena, Germany), the surface characteristics of polymers were examined [39].

\subsection{Differential Scanning Calorimetric Analysis (DSC)}

TGP's thermal analysis was performed with a Shimadzu DSC-60 (Kyoto, Japan). The experiment was conducted at temperatures ranging from 0 to $300{ }^{\circ} \mathrm{C}$ under nitrogen environment (heating rate of $10^{\circ} \mathrm{C} / \mathrm{min}$ and nitrogen purging rate of $50 \mathrm{~mL} / \mathrm{min}$ ) [40]

\subsection{Moisture Content}

The moisture content of the powder was carried out by thermos gravimetric method using IR moisture balance [41].

\section{Results and Discussion}

Tamarindus indica was isolated using distilled water as a solvent system and ethyl alcohol as precipitating agent. Phytochemical investigation showed the presence of carbohydrates while reducing sugar, glucose, tannins, proteins, and polysaccharides were absent. Likewise, the result is found in the study conducted on Azadirachta Indicia and Acacia Nilotica Gum performed by Rishi et al. [42]. Results after the phytochemical test are summarized in Table 1.

Table 1. Different chemical tests employed on TGP.

\begin{tabular}{|c|c|c|}
\hline Test & Observation & Inference \\
\hline Molish's test & $\begin{array}{c}\text { Purple ring at the junction of two } \\
\text { liquid }\end{array}$ & Carbohydrate present \\
\hline Benedict's & Brick red precipitate & Carbohydrate confirmed \\
\hline Osazone test & Needle shaped crystals & $\begin{array}{c}\text { Confirmatory test for fructose and } \\
\text { galactose }\end{array}$ \\
\hline Biuret test & Red color & Protein absent \\
\hline Test for tannins & No greenish precipitate obtained & Tannins absent \\
\hline Sudan red III test & No change in color & Lipids absent \\
\hline Dragendorff's test & No red color obtained & Glycosides absent \\
\hline
\end{tabular}

\subsection{Chemical Characterization of Isolated Gum}

Different chemical tests were performed on the TGP $[43,44]$. From the above test, it was concluded that carbohydrate was present and protein, tannins, lipids and glycosides were absent in the native TGP.

\subsection{Organoleptic Properties and $p H$}

Organoleptic properties of the polymer were observed and found to be acceptable. The color of powdered gum was light brownish. The odour of the polymer was found to be characteristic. The fracture of all the batches was rough. The polymer was soluble in hot water, swell to form a gel in cold water and insoluble in methanol, ethanol, benzene and acetone. Studies conducted on Artocarpus integer gum performed by Farooq et al. and Malviya et al. have also shown the same result and hence support this result $[45,46]$. 


\section{3. $p H$}

The $\mathrm{pH}$ of TGP ( $1 \%$ solution) was found to be $6.70 \pm 0.01$. approx. A similar result has been observed in the study of almond gum conducted by Farooq et al. that found $\mathrm{pH}$ $5.25 \pm 0.813$ which is slightly acidic [47].

\subsection{Viscosity}

The viscosity of fluid decreases with an increase in temperature. The viscosity of liquid depends upon the strength of the attractive forces between the molecules that directly depends on their composition, shape, size and kinetic energy of the molecules, which directly depend on the temperature [46]. This is because when the temperature of the system is raised; energy is added effectively which gives the molecules of the liquid the required energy to overcome the intermolecular force. The temperature dependant viscosity of TGP is shown in Figure 2.

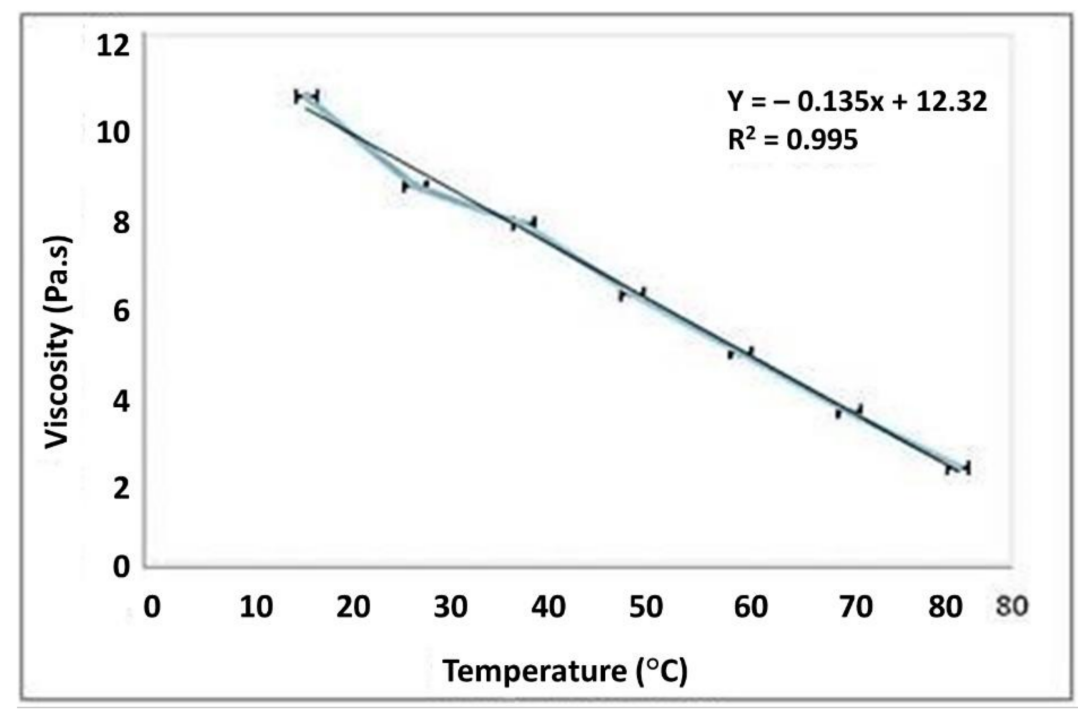

Figure 2. Graphical representation of temperature dependant viscosity (1\% w/v solution of TGP).

\subsection{Surface Tension}

Surface tension of the tamarind seed polymer decreases with an increase in temperature. With the rise in temperature, the kinetic energy of the molecules increases. Therefore, the strength of intermolecular forces decreases resulting in the decrease of surface tension [47]. Therefore, the strength of intermolecular forces decreases resulting in the decrease of surface tension. The temperature-dependent surface tension of TGP has shown in Figure 3.

\subsection{Swelling Index}

The swelling index was found to be $81.83 \%$, which indicates that TGP has a good water intake capacity. This result was supported by Farooq et al. They also observed $87.44 \pm 0.310 \%$ of the swelling index in their study [45]. As discussed in various studies swelling index has been determined for various polysaccharides, so in present investigation swelling index was used as a parameter for the characterization of gum.

\subsection{Micromeritics Properties}

The various physical and functional parameters of the gum are illustrated in Table 2. The results of the Hausner ratio, Carr's index and angle of repose and density revealed that the powder is free-flowing with good flowability. These micromeritics properties of gum were supported by Aroshi Sharma et al. [48]. In a study by Aroshi et al., it was also observed that TGP had the Hausner ratio, Carr's index and angle of repose of 1.25, 18 and $35^{\circ}$, respectively; hence, the obtained results from the present investigation are in accordance with previous studies. 
Table 2. Micromeritics properties of TGP.

\begin{tabular}{|c|c|c|}
\hline Property & Observation & Average \\
\hline Bulk Density $\left(\mathrm{g} / \mathrm{cm}^{2}\right)$ & $0.80 \mathrm{~g} / \mathrm{cm}^{2}$ & $0.80 \pm 0$ \\
\hline Tapped Density $\left(\mathrm{g} / \mathrm{cm}^{2}\right)$ & $\begin{array}{l}0.83 \mathrm{~g} / \mathrm{cm}^{2} \\
0.86 \mathrm{~g} / \mathrm{cm}^{2} \\
0.86 \mathrm{~g} / \mathrm{cm}^{2}\end{array}$ & $2.55 \pm 0.0071$ \\
\hline Carr's Index & $\begin{array}{c}3.75 \\
7.5 \\
7.5\end{array}$ & $6.25 \pm 0.0071$ \\
\hline Hausner's Ratio & $\begin{array}{l}0.96 \\
0.93 \\
0.93\end{array}$ & $0.94 \pm 0.0071$ \\
\hline Angle of repose $(\theta)$ & $\begin{array}{l}0.14 \theta \\
0.13 \theta \\
0.16 \theta\end{array}$ & $0.14 \pm 0.1979$ \\
\hline Aspect Ratio & $\begin{array}{c}0.5 \\
0.75 \\
0.33\end{array}$ & $0.52 \pm 0.071$ \\
\hline Roundness & $\begin{array}{l}0.69 \\
0.76 \\
0.58\end{array}$ & $0.67 \pm 0.073$ \\
\hline Irregularity & $\begin{array}{c}3 \\
3.5 \\
2.66\end{array}$ & $3.05 \pm 0.071$ \\
\hline Equivalent circle diameter & $\begin{array}{c}1.9 \\
7.03 \\
2.34 \\
\end{array}$ & $3.75 \pm 0.072$ \\
\hline Elongation Ratio & $\begin{array}{c}2 \\
1.33 \\
3 \\
0.13\end{array}$ & $2.11 \pm 0.074$ \\
\hline Degree of volume & $\begin{array}{l}0.032 \\
0.064 \\
0.064 \\
\end{array}$ & $0.053 \pm 0.073$ \\
\hline Porosity $(\varepsilon)$ & $0.197 \varepsilon$ & $0.197 \pm 0.072$ \\
\hline Angle of internal friction & $\begin{array}{c}0.946 \\
1.892 \\
2.83\end{array}$ & $1.88 \pm 0.074$ \\
\hline
\end{tabular}

\subsection{Ash Value}

According to Uzma Farroq et al., total ash, acid insoluble ash and water-soluble ash were found to be $15.9 \%, 0.57 \%$ and $3 \%$, respectively; according to Deeksha et al. it was found to be $15.9 \%, 0.57 \%$ and $3 \%$, respectively $[43,49]$. Likewise, the result was observed as described by authors elsewhere.

\subsubsection{Total Ash Values of TG}

The ash value of TG was found to be $14.00 \pm 1.00 \%$. A similar result is observed in the study of Farooq et al. (total ash value 15.9\%) [43]. This value shows that the TG has high inorganic content. The ash content was possibly due to the presence of $\mathrm{Na}^{+}$and $\mathrm{Ca}^{+}$, which were not harmful. The observed ash value indicates that TG was richer in carbohydrates, and TG was served as a good source of dietary need. The total ash, acid insoluble ash and water-soluble ash were found to be $15.9 \%, 0.57 \%$ and $3 \%$, respectively. 


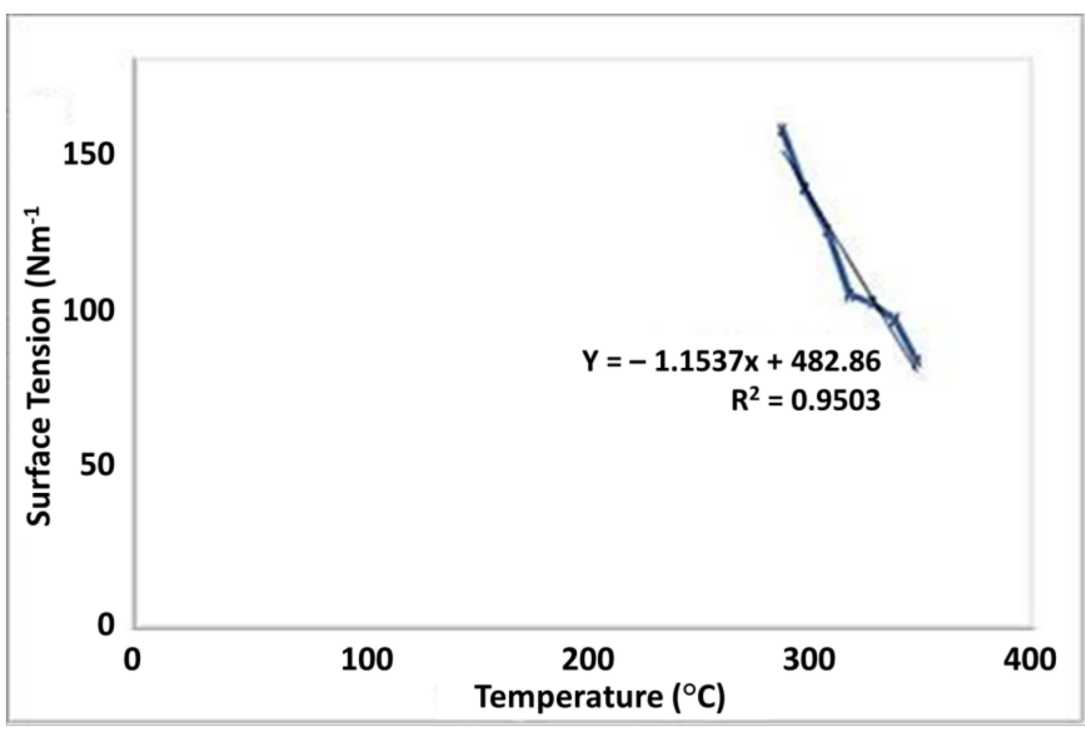

Figure 3. Graphical representation of temperature dependant surface tension.

\subsubsection{Sulphated Ash Value}

This determination was done to measure the number of residual substances which were not volatilized from TGP, when the sample was ignited in the presence of sulphuric acid. The sulphated ash value of TG was found to be $13.00 \pm 0.05 \%$. This value indicates that $13.00 \%$ of inorganic impurities were present in TG.

\subsubsection{Water-Soluble Ash Value}

The water-soluble ash value predicts the nature and purity of crude drugs. The less extractive value, i.e., $<5 \%$, indicates that exhausted materials or adulterants were present in the crude drug. The water-soluble ash value was found to be $7.29 \pm 0.06 \%$. The obtained value showed that TG was pure and free from adulterants or exhausting materials.

\subsubsection{Acid-Insoluble Ash Value}

The observed acid-insoluble ash value was found to be $14.04 \pm 0.57 \%$. This value showed that $14.04 \%$ of the proportion of the sample was not hydrolyzed by $72 \%$ of sulphuric acid and subsequently not volatilized upon the incineration of TG residue. All detail of found ash value has shown in Table 3.

Table 3. Details of ash values of TG.

\begin{tabular}{ccc}
\hline S.no & Parameters & Observation \\
\hline 1 & Total ash value $(\%)$ & $14.00 \pm 1.00$ \\
2 & Sulphated ash (\%) & $13.00 \pm 0.05$ \\
3 & Water-soluble ash (\%) & $7.29 \pm 0.06$ \\
5 & Acid-insoluble ash (\%) & $14.04 \pm 0.57$ \\
\hline
\end{tabular}

\subsection{Particle Size Analysis}

The particle size of TG particles was found to be $88.54 \pm 0.76 \mu \mathrm{m}$. It indicates that TG has coarse particle lies in-between its usual particle size range. The average size of $44.31 \pm 9.43 \mu \mathrm{m}$ was found in a study by Sumedha Pant et al., which supports this result [50]. The particle size distribution is shown in Table 4. 
Table 4. Particle size analysis of TG.

\begin{tabular}{cc}
\hline Size Range $(\mu \mathrm{m})$ & No. of Particles \\
\hline $0-20$ & 30 \\
$20-40$ & 67 \\
$40-80$ & 114 \\
$80-90$ & 90 \\
$>90$ & 40 \\
\hline
\end{tabular}

In the present study, the particle size of TG was found to be $88.54 \pm 0.76 \mu \mathrm{m}$, while the organic material particle size which improves the mixed maricite's efficiency and porosity of TG was found to be $0.197 \pm 0.072 \varepsilon$, which proves that TG has coarse particle which is satisfactory for the preparation of dosage form. The organic material of commercial carbon electrodes has a porosity of $0.76 \mathrm{~cm}^{3} / \mathrm{g}$ [51].

\subsection{FT-IR Spectral Analysis}

According to a study by Nair et al., the FTIR spectrum of nebivolol depicts characteristic peaks at $3209.93 \mathrm{~cm}^{-1}$ (O-H stretching), $2873.42 \mathrm{~cm}^{-1}$ (C-H stretching), $1491.67 \mathrm{~cm}^{-1}$ (C=C stretching), $1349.93 \mathrm{~cm}^{-1}$ (C-N stretching), and $1141.67 \mathrm{~cm}^{-1}$ (C-O stretching) [52,53]. Based on the literary facts the presence of IR bands at $3462,3287,3076,2854,1711$ and $1498 \mathrm{~cm}^{-1}$ in FTIR spectrum of TGP were assigned to $\mathrm{O}-\mathrm{H}, \mathrm{N}-\mathrm{H}, \mathrm{C}-\mathrm{H}, \mathrm{C}=\mathrm{O}$ stretch and $\mathrm{C}=\mathrm{C}$ functional groups of the TGP [54]. The result of the IR spectral study was also supported by the study performed by Kailas et al. and Chawananorasest et al. [55,56]. The native TGP does not contain any nitrogenous group in its structure. The main groups present in the TGP are carboxylic acid group (-COOH) and hydroxyl groups $(-\mathrm{OH})$ (Figure 4). Due to this, the $\mathrm{OH}$ stretching is predominantly shown at $3416 \mathrm{~cm}^{-1}$ and $\mathrm{C}=\mathrm{O}$ groups are highly dominating at about $1600-1800 \mathrm{~cm}^{-1}[57,58]$.

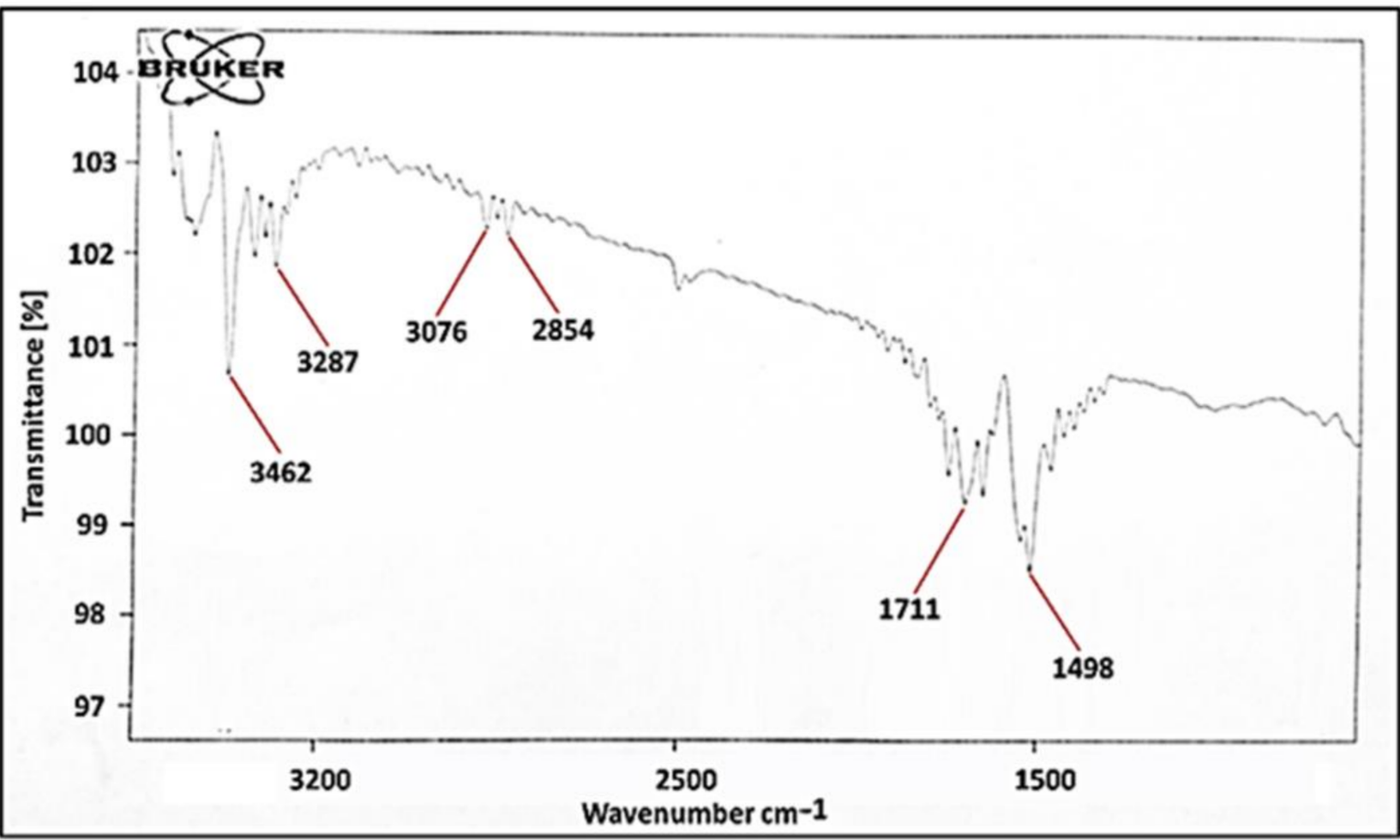

Figure 4. FTIR spectra of TGP. 


\subsection{Contact Angle Determination}

Copper plate was utilized for the drop formation. Further, the drop was vacuum dried and the plate was kept under the NYKON microlense from a distance of $22 \mathrm{~cm}$ (object piece). PHANTOM HIGH PEAK camera-1300 was utilized for the whole procedure. According to Malviya et al., the contact angle $<90^{\circ}$ indicates favorable wetting and good spreading of liquid over the surface; however, the contact angle $>90^{\circ}$ indicates unfavorable surface wetting and formation of a compact droplet by liquid over a surface. The solubility of the polymer is inversely proportional to the contact angle. In the study of Malviya et al., NGP have a contact angle of $75.14 \pm 2.61^{\circ}$, likewise the contact angle of the TGP was found to be $73.682 \pm 2^{\circ}$, as described by authors elsewhere. A photograph image for the same is given in Figure 5 [59].

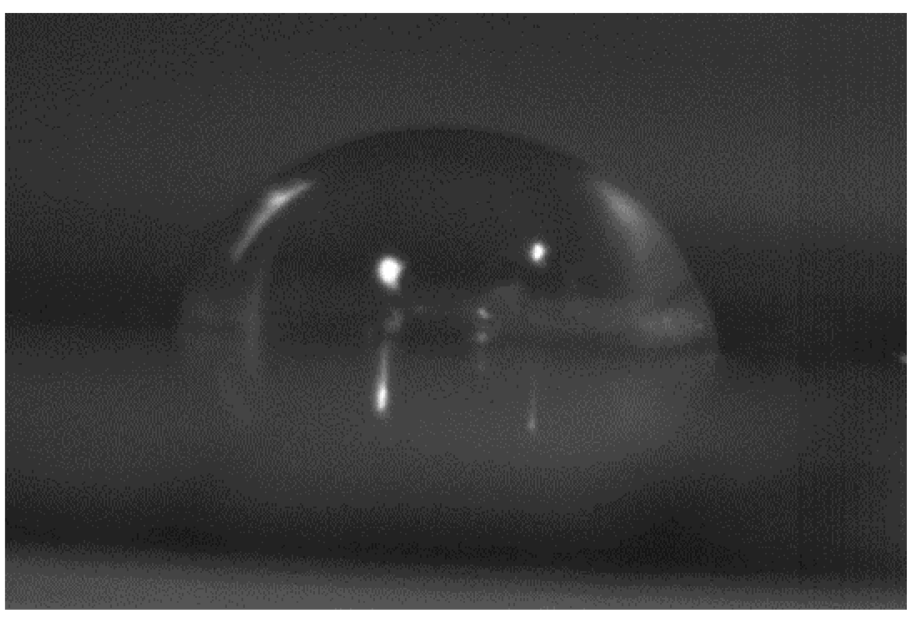

Figure 5. Contact angle measurement of TGP.

\subsection{Scanning Electron Microscopy (SEM)}

Mainly for the determination of the structural morphology of the native and modified sample, SEM is applied. Both the samples were gold coated to increase the conductivity of the electron beam passing them. The SEM of the TGP is shown in Figure 6. Likewise, in the result of the SEM analysis performed by Samrot et al. they observed that particles were spherical and that TGP powder has two types of particles, smaller sized particles with rough rounded edges and larger-sized particles with irregular shapes with smooth surfaces [60]. SEM results show that the TGP has sizes up to 30-90 $\mu \mathrm{m}$. The SEM result was also supported by Malsawmtluangi et al., in which the investigator also observed smooth surfaces with some irregularities in particles [61].

\subsection{Differential Scanning Calorimetric Analysis (DSC)}

The DSC of the native tamarind seed polymer was determined. The DSC of the pure and modified sample was in the heating range of $0-70{ }^{\circ} \mathrm{C}$ and heating rate of $10^{\circ}$ per $10 \mathrm{~min}$. The peak showing the melting point of the TGP was shown in Figure 7. The sharp endothermic peak at $229.31^{\circ} \mathrm{C}$ was found in a study of Nair et al.; similarly, as described by the author elsewhere, in the case of TGP a sharp exothermic peak was evolved at $350{ }^{\circ} \mathrm{C}$ that shows its crystalline nature [52]. This study is also supported by Gaur et al., in which a sharp exothermic peak was found at $350^{\circ} \mathrm{C}$, which support its crystalline nature [62]. According to study of Malviya et al., a thermogram of NG-g-Am shows a single sharp exothermic peak at $249^{\circ} \mathrm{C}$. The sharp exothermic peaks of N1 show the crystalline nature of acrylamide graft copolymers that also supports its crystalline nature [63-65]. 


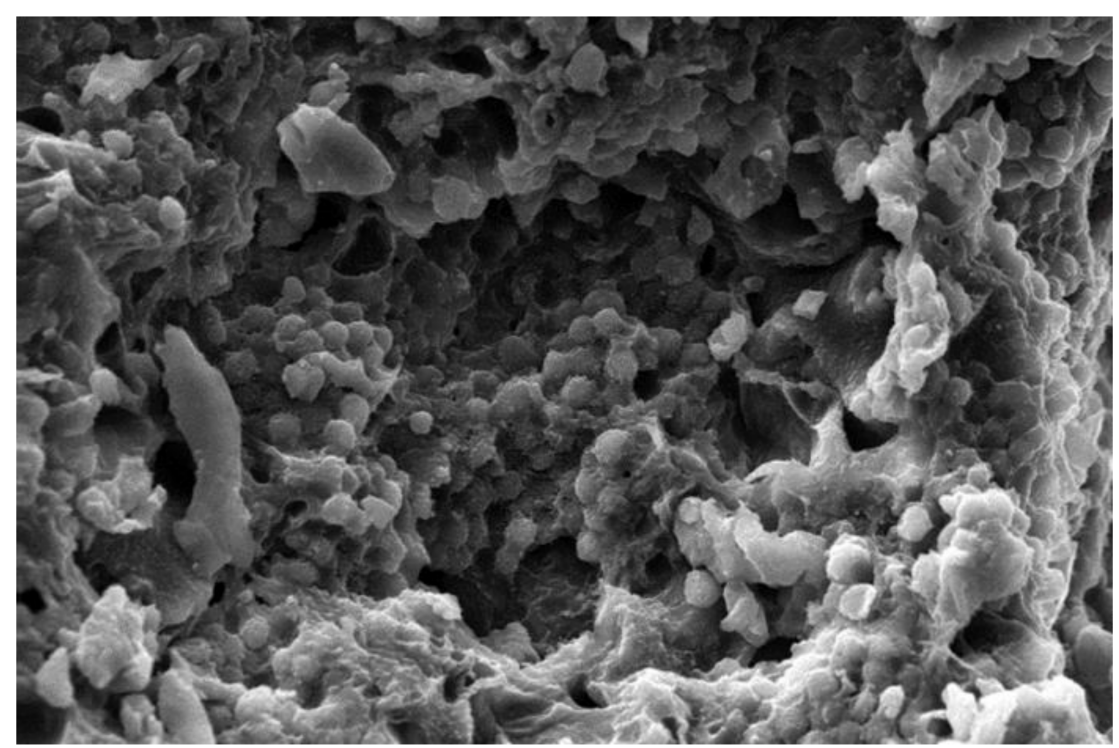

Figure 6. SEM image of TGP.

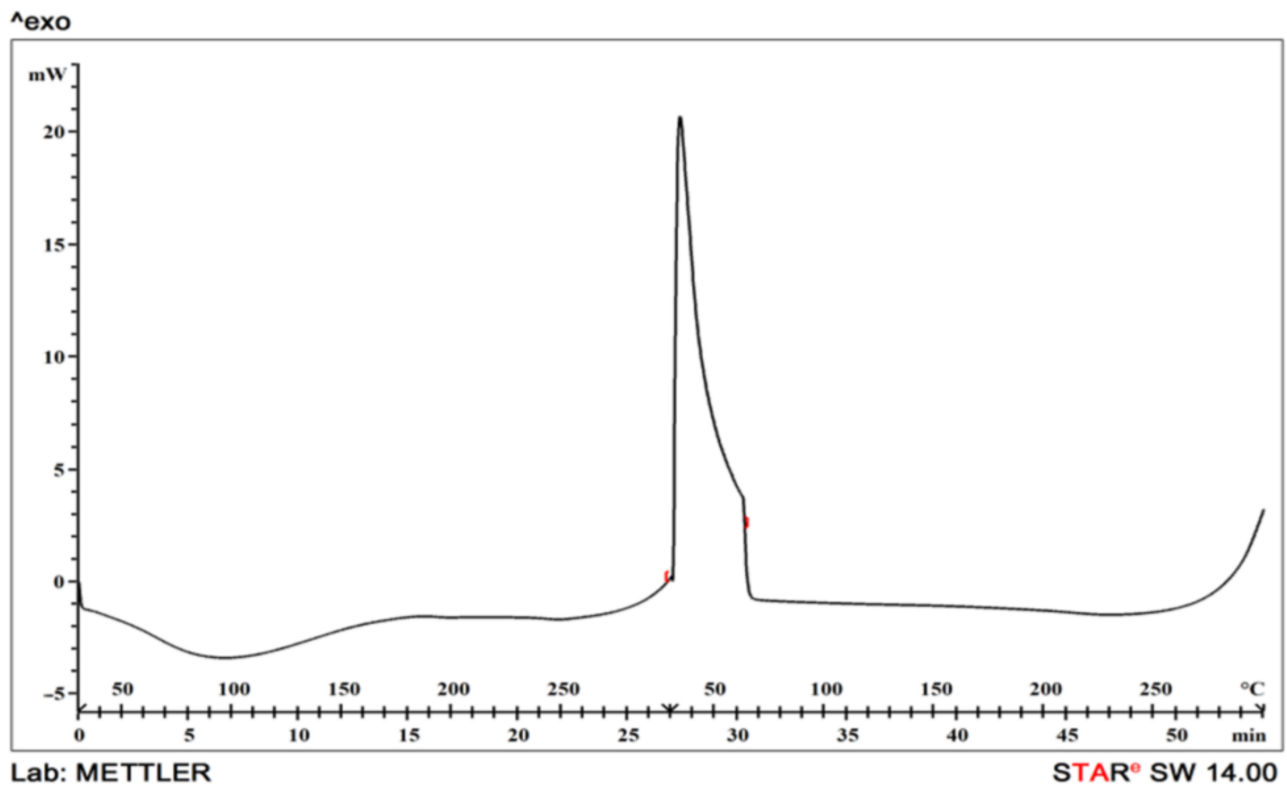

Figure 7. DSC thermogram of TGP.

\subsection{Moisture Content}

The moisture content was found to be $8.2 \%$, indicating that it has good stability for dosage from.

\section{Biomedical Application of TGP}

Due to multifunctional features, polysaccharide-based composites generated from natural sources have been widely exploited, particularly in drug delivery systems and biomedical applications. These materials are well-known and in high demand because of their biochemical capabilities, which are similar to those of animal cells and the human body. Natural polysaccharide-based nanomaterials may have a wide range of biological properties, including biocompatibility, bioavailability, and sustainability [66]. TGP is used as suspending and emulsifying agent in liquid oral dosage forms, binder in solid dosage form, novel controlled release modifiers, matrix oral drug release modifier, buccal drug release modifier, ophthalmic drug release modifier, carrier for colon targeted drug delivery [67-69]. 


\section{Conclusions}

TGP was extracted from the crude seed of Tamarindus indica and it was observed from research work that the gum of tamarind has carbohydrates. All the organoleptic properties evaluated were found to be acceptable. The color of powder was light brownish, odour was characteristic, fracture was rough. The $\mathrm{pH}$ was found to be almost neutral i.e., $6.70 \pm 0.01$. Surface tension of tamarind seed polymer decreases with an increase in temperature. Swelling index reveals that the gum swells well in water was found to be $87 \%$. The bulk density was found to be $0.80 \pm 0$, tapped density was $2.55 \pm 0.0071$, carr's index was $6.25 \pm 0.0071$, Hausner's ratio was $0.94 \pm 0.0071$, angle of repose was $0.14 \pm 0.1979$, aspect ratio was $0.52 \pm 0.071$, roundness was $0.67 \pm 0.073$, irregularity was $3.05 \pm 0.071$, equivalent circle diameter was $3.75 \pm 0.072$, elongation ratio was $2.11 \pm 0.074$, degree of volume $0.053 \pm 0.073$, porosity was $0.197 \pm 0.072$, angle of internal friction was $1.88 \pm 0.074$ obtained. The total ash value was within the limits and found to be $14.00 \pm 1.00$, sulphated ash value was $13.00 \pm 0.05$, water-soluble ash was $7.29 \pm 0.06$ and acid-insoluble ash was $14.04 \pm 0.57$ obtained. The particle size of TGP particles was found to be satisfactory which indicates that TGP has coarse particles that are in-between its usual particle size range. The IR spectra confirmed the presence of alcohol, amines, ketones, anhydrides. The contact angle of the TGP was found out to be $<90^{\circ}$, which indicates favorable wetting and good spreading of liquid over the surface. The SEM results showed a smooth surface with some irregularities in particles. The DSC of the sample was in the heating range of $0-70{ }^{\circ} \mathrm{C}$ and showed a sharp exothermic peak at $350{ }^{\circ} \mathrm{C}$ that displays its crystalline nature. Hence from the result, it was concluded that the evaluated properties showed that gum derived from tamarind seed has acceptable $\mathrm{pH}$ and organoleptic properties and can be used as a pharmaceutical excipient to formulate dosage forms. Extraction of gum from seed shows better management of waste material. So, extracted seed gum may be a suitable substitute for pre-established natural gums such as guar gum, gum acacia and starch etc.

Author Contributions: Conceptualization, R.M., S.S., S.F. and N.K.F.; investigation, R.M., S.S., S.F. and N.K.F.; resources, R.M., S.S., S.F., V.S., K.V.S., A.K.A., M.S., D.H.K., S.C., O.P., D.U.M. and N.K.F.; data curation, R.M., S.S., S.F., V.S., K.V.S., A.K.A., M.S., D.H.K., S.C., O.P., D.U.M. and N.K.F.; writing-original draft preparation, R.M., S.S., S.F. and N.K.F.; writing-review and editing, R.M., S.S., S.F., V.S., K.V.S., A.K.A., M.S., D.H.K., S.C., O.P., D.U.M. and N.K.F. All authors have read and agreed to the published version of the manuscript.

Funding: This research received no external funding.

Institutional Review Board Statement: Not applicable.

Informed Consent Statement: Not applicable.

Data Availability Statement: The data presented in this study are available on request from the corresponding author.

Acknowledgments: All the authors of this manuscript are thankful to their respective Departments/Universities for successful completion of this study.

Conflicts of Interest: The authors declare no conflict of interest.

\section{References}

1. Durai, R.D.; Rajalakshmi, G.; Joseph, J.; Kanchalochana, S.; Hari, V. Tamarind seed polysaccharide: A promising natural excipient for pharmaceuticals. Int. J. Green Pharm. 2012, 6, 270. [CrossRef]

2. Shankracharyan, B. Tamarind chemistry, technology and uses: A critical Appraisal. J. Food Sci. Technol. 1998, 35, 193-208.

3. Shao, H.; Zhang, H.; Tian, Y.; Song, Z.; Lai, P.F.H.; Ai, L. Composition and Rheological Properties of Polysaccharide Extracted from Tamarind (Tamarindus indica L.) Seed. Molecules 2019, 24, 1218. [CrossRef]

4. Sharma, V.; Patnaik, P.; Senthilguru, K. Preparation and characterization of novel tamarind gum-based hydrogels for anti-microbial drug delivery applications. Chem.Pap. 2018, 72, 2101-2113. [CrossRef]

5. Malviya, R.; Raj, S.; Fuloria, S.; Subramaniyan, V.; Sathasivam, K.; Kumari, U.; Meenakshi, D.U.; Porwal, O.; Kumar, D.H.; Singh, A.; et al. Evaluation of Antitumor Efficacy of Chitosan-Tamarind Gum Polysaccharide Polyelectrolyte Complex Stabilized Nanoparticles of Simvastatin. Int. J. Nanomed. 2021, 16, 2533-2553. [CrossRef] [PubMed] 
6. Nayak, A.K.; Pal, D. Functionalization of Tamarind Gum for Drug Delivery; Springer International Publishing: New York, NY, USA, 2017; pp. 25-56. [CrossRef]

7. Malviya, R.; Jha, S.; Fuloria, N.K.; Subramaniyan, V.; Chakravarthi, S.; Sathasivam, K.; Kumari, U.; Meenakshi, D.U.; Porwal, O.; Sharma, A.; et al. Determination of Temperature-Dependent Coefficients of Viscosity and Surface Ten-sion of Tamarind Seeds (Tamarindus indica L.). Polymers 2021, 18, 13-610.

8. Malviya, R.; Srivastava, P.; Bansal, M.; Sharma, P.K. Formulation, evaluation and comparison of sustained release matrix tablets of diclofenac sodium using tamarind gum as release modifier. Asian J. Pharm. Clin. Res. 2010, 3, 238-241.

9. Da Silva, D.A.; Melo Aires, G.C.; Silva Pena, R.D. Innovation in the Food Sector Through the Valorization of Food and Agro-Food By-Products; Gums-Characteristics and Applications in the Food Industry; IntechOpen: London, UK, 2020.

10. Singh, R.; Malviya, R.; Sharma, P.K. Extraction and Characterization of Tamarind Seed Polysaccharide as a Pharmaceutical Excipient. Pharm. J. 2011, 3, 17-19. [CrossRef]

11. Sumathi, S.; Ray, A.R. Release behaviour of drugs from tamarind seed polysaccharide tablets. J. Pharm. Pharm. Sci. 2002, 5, 12-18.

12. Prabhanjan, H. Studies on Modified Tamarind Kernel Powder. Part I: Preparation and Physicochemical Properties of Sodium Salt of Carboxymethyl. Derivatives 1989, 41, 409-414. [CrossRef]

13. Rao, P.S.; Beri, R.M. Acetylation of tamarind seed Jellose. Proc. Math. Sci. 1955, 42, 199-203. [CrossRef]

14. Prabhanjan, H.; Ali, S.Z. Studies on rheological properties of tamarind kernel powder, its derivatives and their blends with maize starch. Carbohydr. Polym. 1995, 28, 245-253. [CrossRef]

15. Yadav, A.; Vishwakarma, R.K.; Mishra, S.K.; Shukla, A.K. Isolation and characterization of tamarind seed gum as pharmaceutical excipient. Int. J. Health Clin. Res. 2020, 3, 49-57.

16. Lynch, C.R.; Kondiah, P.P.D.; Choonara, Y.E.; Du Toit, L.C.; Ally, N.; Pillay, V. Hydrogel Biomaterials for Application in Ocular Drug Delivery. Front. Bioeng. Biotechnol. 2020, 8, 228. [CrossRef] [PubMed]

17. Kaur, H.; Ahuja, M.; Kumar, S.; Dilbaghi, N. Carboxymethyl tamarind kernel polysaccharide nanoparticles for ophthalmic drug delivery. Int. J. Biol. Macromol. 2012, 50, 833-839. [CrossRef]

18. Dubashynskaya, N.; Poshina, D.; Raik, S.; Urtti, A.; Skorik, Y.A. Polysaccharides in Ocular Drug Delivery. Pharmaceutics 2020, 12, 22. [CrossRef]

19. Aly, A.S. Self-dissolving chitosan. I. Preparation, characterization and evaluation for drug delivery system. Angew. Makromol. Chem. 1998, 259, 13-18. [CrossRef]

20. Abdulhady, S.S.; Ibrahim, K.M.H. Preparation and evaluation of mebeverine hydrochloride as mucoadhesive buccal tablet for local anesthesia. Trop. J. Pharm. Res. 2017, 16, 1805. [CrossRef]

21. Deogire, S.; Mahaparale, S. Development and Evaluation Sustained release Matrices of Lamivudine by Using Synthetic Pol-ymer. Intern. J. Pharm. Res. Health Sci. 2014, 2, 233.

22. Bhosale, R.R.; Ali, R.; Osmani, M.; Moin, A. Natural gums and mucilages: A review on multifaceted excipients in pharmaceu-tical science and research. Intern. J. Pharm. Res. Health Sci. 2015, 6, 901-912.

23. Mahammed, N.; Deshpande, R.D.; Gowda, D.V. Modified polysaccharides as drug delivery: Review. Intern. J. Pharm. Res. Health Sci. 2011, 11, 42-47.

24. Glycoside Cardiac Glycosides Classification and Chemical Tests for Cardiac Glycosides. Available online: http://www. yourarticlelibrary.com/biology/glycoside/cardiac-glycosides-classification-and-chemical-tests-for-cardiac-glycosides/49746/ (accessed on 14 May 2021).

25. Available online: https://www.google.co.in/search?q=test+for+lipids+pdf\&oq=test+for+lpids+pdf\&gs_l=psyab.3..0i19k1j0i2 2i30i19k113.1163.2057.0.2457.4.4.0.0.0.0.180.712.0j4.4.0...0...1.1.64.psyab..0.4.712.TJ4AgyedDDM (accessed on 5 May 2021).

26. Anema, S.G.; Lowe, E.K.; Li, Y. Effect of $\mathrm{pH}$ on the viscosity of heated reconstituted skim milk. Int. Dairy J. 2004, 14, 541-548. [CrossRef]

27. Radhika, P.R.; Kharkate, P.R.; Thangavel, S. Formulation of Aceclofenac Sustained Release Matrix Tablet using Hydrophilic Natural Gum. Intern. J. Pharm. Res. Health Sci. 2011, 2, 851.

28. Stokes, G.G. On the Effect of the Internal Friction of Fluids on the Motion of Pendulums; Cambridge University Press: Cambridge, UK, 2010; pp. 1-10. [CrossRef]

29. Nayak, B.; Pattanayak, D.; Ellaiah, P.; Das, S. Formulation design preparation and in vitro characterization of nebivolol transdermal patches. Asian J. Pharm. 2011, 5, 175. [CrossRef]

30. Nauib, H.F.J. Chemically induced graft copolymerization of itaconic acid onto sisal fibers. Polymer Res. $2002,9,207$.

31. Yoshida, T.; Hattori, K.; Sawada, Y.; Choi, Y.; Uryu, T. Graft copolymerization of methyl methacrylate onto curdlan. J. Polym. Sci. Part A Polym. Chem. 1996, 34, 3053-3060. [CrossRef]

32. Durcilene, A.D.S.; Regina, C.M.P.; Judith, P.A. Graft copolymerisation of acrylamide onto cashew gum. Euro. Poly. J. 2007, 43, 2620-2629.

33. Malviya, R.; Srivastava, P. Preparation, Characterization and Application of Chitosan-Alginate Based Polyelectrolyte Complex as Fast Disintegrating Drug Delivery Carrier. Polym. Med. 2011, 41, 45-54.

34. Bodhmage, A. Correlation between physical properties and flowability indicators for fine powders. Master's Thesis, Saskatchewan University, Saskatoon, SK, Canada, 2006.

35. Sandler, N.; Wilson, D. Prediction of granule packing and flow behaviour based on particle size and shape analysis. J. Pharm. Sci. 2010, 99, 958-968. [CrossRef] 
36. Patel, A.; Shah, D.; Desai, T.R.; Noolvi, M.N. Mucoadhesive buccal films based on chitosan and carboxymethylated Feronia limonia fruit pulp mucilage interpolymer complex for delivery of opioid analgesics. Asian J. Pharm. 2016, 10, $137-143$.

37. Potaś, J.; Szymańska, E.; Basa, A.; Hafner, A.; Winnicka, K. Tragacanth Gum/Chitosan Polyelectrolyte Complexes-Based Hy-drogels Enriched with Xanthan Gum as Promising Materials for Buccal Application. Materials 2021, 14, 86. [CrossRef]

38. Morse, P.; Loxley, A. Light microscopic determination of particle size distribution in an aqueous gel. Drug Deliv. Technol. 2009, 9, $1-5$.

39. Malviya, R.; Awasthi, R.; Sharma, P.K.; Dubey, S.K. Stabilization of Etoricoxib Nanosuspension Using Acacia chundra Gum and Copolymers: Preparation, Characterization, and In Vitro Cytotoxic Study. Assay Drug Dev. Technol. 2021, 19, 306-321. [CrossRef]

40. Naghshbandi, M.P.; Moghimi, H. Stabilization of phytase on multi-walled carbon nanotubes via covalent immobilization. Method. Enzym. 2020, 630, 431-451.

41. Soumya, R.S.; Ghosh, S.; Abraham, E.T. Preparation and characterization of guar gum nanoparticles. Int. J. Biol. Macromol. 2010, 46, 267-269. [CrossRef] [PubMed]

42. Sharma, P.K.; Dubey, S.K. Microwave Facilitated Green Synthesis and Characterization of Acrylamide Grafted Copolymer of Kheri (Acacia chundra) Gum Polysaccharide. Nat. Prod. J. 2020, 10, 467-487. [CrossRef]

43. Saikia, F.; Ali, J.O.N.A.B.; Das, B.I.S.W.A.J.I.T. Isolation and characterization of tamarind seed polysaccharides-A natural release retardant. Int. J. Curr. Pharm. Res. 2017, 9, 114-117. [CrossRef]

44. Kumar, P.; Kumar, R.; Bala, V.; Singh, H.; Singh, S. Purification characterization and analytical evaluation of suspending properties of azadirachta indicia and acacia nilotica gum. World J. Pharm. Res. 2019, 8, 812-825.

45. Farooq, U.; Malviya, R.; Sharma, P.K. Extraction and characterization of artocarpus integer gum as pharmaceutical excipient. Polym. Med. 2014, 44, 69-74.

46. Malviya, R.; Sharma, P.; Dubey, S. Kheri (Acacia chundra, family: Mimosaceae) gum: Characterization using analytical, mathematical and pharmaceutical approaches. Polym. Med. 2017, 47, 65-76. [CrossRef]

47. Farooq, U.; Malviya, R. Extraction and Characterization of Almond (Prunus sulcis) Gum Pharmaceutical Excipient. Am.-Eurasian J. Agric. Environ. Sci. 2014, 14, 269-274. [CrossRef]

48. Vanerek, A.; Van de Ven, T.G.M. Coacervate complex formation between cationic polyacrylamide and anionic sulfonated kraft lignin. Colloids Surf. 2006, 273, 55-62. [CrossRef]

49. Patel, Y.; Katsuyoshi, N. Gelation and gel properties of polysaccharides gellan gum and tamarind xyloglucan. J. Biol. Macromol. 2011, 5, 47.

50. Sharma, A.; Pravin, R.B.; Annapure, U.S. Purification and physicochemical characterization of Prunus domestica exudate gum polysaccharide. Carbohydr. Polym. Technol. Appl. 2020, 1, 100003. [CrossRef]

51. Malviya, R.; Sharma, P.K. Extraction and Characterization of Aegle Marmelos Derived Polymer as a Pharmaceutical Excipient. Polim. Med. 2014, 44, 141-146.

52. Sumedha, P.; Malviya, R.; Sharma, P. Extraction and Characterization of Moringo olifera Gum as Pharmaceutical Sus-pending Agent. Nat. Prod. J. 2015, 5, 109-114.

53. Sundaram, M.M.; Watcharatharapong, T.; Chakraborty, S.; Ahuja, R.; Duraisamy, S.; Rao, P.T.; Munichandraiah, N. Synthesis, and crystal and electronic structure of sodium metal phosphate for use as a hybrid capacitor in non-aqueous electrolyte. Dalton Trans. 2015, 44, 20108-20120. [CrossRef]

54. Nair, A.B.; Shah, J.; Aljaeid, B.M.; Al-Dhubiab, B.E.; Jacob, S. Gellan Gum-Based Hydrogel for the Transdermal Delivery of Nebivolol: Optimization and Evaluation. Polymers 2019, 11, 1699. [CrossRef] [PubMed]

55. Rezaei, A.; Nasirpour, A.; Tavanai, H. Fractionation and some physicochemical properties of almond gum (Amygdalus communis L.) exudates. Food Hydrocoll. 2016, 60, 461-469. [CrossRef]

56. Mali, K.K.; Dhawale, S.C.; Dias, R.J. Extraction, Characterization and Functionalization of Tamarind Gum. Res. J. Pharm. Tech. 2019, 12, 1745-1752. [CrossRef]

57. Chawananorasest, K.; Saengtongdee, P.; Kaemchantuek, P. Extraction and Characterization of Tamarind (Tamarind indica L.) Seed Polysaccharides (TSP) from Three Difference Sources. Molecules 2016, 21, 775. [CrossRef] [PubMed]

58. Malviya, R.; Sharma, P.K.; Dubey, S.K. Microwave-assisted preparation of biodegradable, hemocompatible, and antimicrobial neem gum-grafted poly (acrylamide) hydrogel using (3)2 factorial design. Emergent Mater. 2019, 2, 95-112. [CrossRef]

59. Wickramaarachchi, K.; Sundaram, M.M.; Henry, D.J.; Gao, X. Alginate Biopolymer Effect on the Electrodeposition of Manganese Dioxide on Electrodes for Supercapacitors. ACS Appl. Energy Mater. 2021, 4, 7040-7051. [CrossRef]

60. Ramkumar, R.; Sundaram, M.M. A biopolymer gel-decorated cobalt molybdate nanowafer: Effective graft polymer cross-linked with an organic acid for better energy storage. New J. Chem. 2016, 40, 2863-2877. [CrossRef]

61. Fuloria, N.K.; Fuloria, S. Structural Elucidation of Small Organic Molecules by 1D, 2D and Multi Dimensional-Solution NMR Spectroscopy. J. Anal. Bioanal. Tech. 2013, 4. [CrossRef]

62. Samrot, A.V.; Angalene, J.L.A.; Roshini, S.M.; Stefi, S.M.; Preethi, R.; Raji, P.; Kumar, A.M.; Kumar, S.S. Purification, characterization and exploitation of Azadirachta indica gum for the production of drug loaded nanocarrier. Mater. Res. Express 2020, 7 , 055007. [CrossRef]

63. Malsawmtluangi, C.; Thanzami, K.; Lalhlenmawia, H.; Selvan, V.; Palanisamy, S.; Kandasamy, R.; Pachuau, L. Physico-chemical characteristics and antioxidant activity of Prunus cerasoides D. Don gum exudates. Int. J. Biol. Macromol. 2014, 69, 192-199. [CrossRef] 
64. Gaur, N.; Parvez, N. extraction and characterization of polysaccharide from tamarind seed for its pharmaceutical applications. World J. Pharm. Res. 2019, 8, 1219-1230.

65. Kumar, A.; Singh, K.; Ahuja, M. Xanthan-g-poly (acrylamide): Microwave-assisted synthesis, characterization and in vitro release behavior. Carbohydr. Polym. 2009, 76, 261-267. [CrossRef]

66. Giri, T.K.; Pradhan, M.; Tripathi, D.K. Synthesis of graft copolymer of kappa-carrageenan using microwave energy and studies of swelling capacity, flocculation properties, and preliminary acute toxicity. Turk. J. Chem. 2016, 40, 283-295. [CrossRef]

67. Malviya, R.; Sharma, P.; Dubey, S. Microwave controlled green synthesis of acrylamide graft copolymers of Azadirachita indica gum for the waste water management. Curr. Appl. Polym. Sci. 2018, 2, 130-149. [CrossRef]

68. Muhamad, I.I.; Lazim, N.A.M.; Selvakumaran, S. Natural polysaccharide-based composites for drug delivery and biomedical applications. In Natural Polysaccharides in Drug Delivery and Biomedical Applications; Academic Press: Cambridge, MA, USA, 2019; pp. 419-440. [CrossRef]

69. Nayyar, T.; Sabharwal, S.; Jain, U.K.; Taneja, R. Recent approaches and pharmaceutical applications of natural polysaccha-rides: A review. Int. J. Pharm. Sci. Res. (IJPSR) 2015, 6, 4904-4919. 